\title{
Case Report: Aortitis associated with rheumatoid arthritis: A \\ challenging rheumatoid vasculitis presentation [version 1;
}

\section{peer review: 2 approved with reservations]}

\section{Zeineb Teyeb(1),2, Mohamed Ben Salah(i)2,3, Lobna Kharrat1,2, Imen Abdellali1,2, Taieb Jomni1,2, Mohamed Hedi Douggui1,2}

${ }^{1}$ Department of Internal Medicine, Internal Security Forces Hospital, Tunis, Tunisia

${ }^{2}$ Faculty of Medicine of Tunis, University of Tunis El Manar, Tunis, Tunisia

${ }^{3}$ Department of Orthopedic Surgery, Chales Nicole Hospital, Tunis, Tunisia

V1 First published: 26 Nov 2020, 9:1370

https://doi.org/10.12688/f1000research.26929.1

Latest published: 26 Nov 2020, 9:1370

https://doi.org/10.12688/f1000research.26929.1

\section{Abstract}

Rheumatoid vasculitis (RV) is a rare but serious extra-articular manifestation of rheumatoid arthritis (RA). Its varied clinical presentation makes it hard to diagnose and treat. Hereby we describe a case of an aortitis revealing $\mathrm{RV}$, which is a rare presentation of a rare complication of RA. A 56-year-old man with rheumatoid arthritis treated with methotrexate presented with fever, chest pain and arthritis. Blood tests revealed inflammatory syndrome associated with cholestasis. The diagnosis of pericarditis associated with aortitis was retained. Cholestasis was mostly due to methotrexate. The patient was treated with cyclophosphamide pulses and high doses of prednisolone. The patient was in complete remission of articular and extra-articular manifestations after two months of treatment.

\section{Keywords}

rheumatoid arthritis, rheumatoid vasculitis, aortitis, immunosuppressive therapy, case report

\section{Open Peer Review \\ Approval Status? ? \\ 12

version $1 ?$ ? \\ 26 Nov 2020 \\ 1. Dionicio Ángel Galarza-Delgado (D), \\ Hospital Universitario "Dr. José Eleuterio \\ González", Monterrey, Mexico \\ 2. Shunta Kaneko (D), Tokyo Yamate Medical \\ Center, Tokyo, Japan}

Any reports and responses or comments on the article can be found at the end of the article.

Corresponding author: Zeineb Teyeb (zeinebteyebbs@gmail.com)

Author roles: Teyeb Z: Project Administration, Writing - Review \& Editing; Ben Salah M: Writing - Review \& Editing; Kharrat L: Writing Original Draft Preparation; Abdellali I: Software; Jomni T: Validation; Douggui MH: Supervision

Competing interests: No competing interests were disclosed.

Grant information: The author(s) declared that no grants were involved in supporting this work.

Copyright: ( 2020 Teyeb Z et al. This is an open access article distributed under the terms of the Creative Commons Attribution License, which permits unrestricted use, distribution, and reproduction in any medium, provided the original work is properly cited.

How to cite this article: Teyeb Z, Ben Salah M, Kharrat L et al. Case Report: Aortitis associated with rheumatoid arthritis: A challenging rheumatoid vasculitis presentation [version 1; peer review: 2 approved with reservations] F1000Research 2020, 9 :1370 https://doi.org/10.12688/f1000research.26929.1

First published: 26 Nov 2020, 9:1370 https://doi.org/10.12688/f1000research.26929.1 


\section{Introduction}

Rheumatoid arthritis (RA) is a connective tissue disease predominantly affecting the joints. Extra-articular manifestations develop in up to $40 \%$ of cases $^{1}$, of which rheumatoid vasculitis (RV) is the most serious. The widespread vascular involvement, which effects not only the synovia but also other organs such as the skin, eye and nerves, can be life threatening. Mortality can reach up to $40 \%$ within five years of disease onset $^{2}$. Fortunately, RV is a rare complication that occurs in $1-5 \%$ of RA patients ${ }^{3}$. It commonly affects small and medium blood vessels ${ }^{4}$. Large vessel vasculitis is unusual during RA. Hereby we describe a case of an aortitis revealing RV, which is a rare presentation of a rare complication of RA.

\section{Case description}

Patient information and clinical findings

A 54-year-old man, a North African policeman with a personal history of smoking and pulmonary tuberculosis in 1991 was diagnosed in 2009 with seropositive and erosive RA associated with Sjögren's syndrome. He was being treated with methotrexate (25mg/week). In November 2019, the patient presented to our hospital with fever, fatigue and chest pain that had started one week prior. Physical examination found a high temperature of $38.5^{\circ} \mathrm{C}$. Systolic blood pressure was $100 \mathrm{mmHg}$ and diastolic blood pressure was $60 \mathrm{mmHg}$ in both arms. He had tachycardia, with a heart rate of 115 beats per minute. There were no signs of heart failure and respiratory rate was normal. Mobilization of the wrists, elbows and shoulders was painful, with a swollen right wrist. He had a dislocation of the right ulnar styloid. He had rheumatoid nodules on the outer side of both elbows. The rest of the physical examination was normal.

\section{Diagnostic assessment}

An electrocardiogram showed atrial fibrillation with a heart rate of 115 beats per minutes associated with diffuse ST-segment elevation with upward concavity.

Blood tests showed hyper leukocytosis at $11000 / \mathrm{mm}^{3}$, C-reactive protein (CRP) levels of $117 \mathrm{mg} / \mathrm{l}$, an erythrocyte sedimentation rate (ESR) of $118 \mathrm{~mm}$ and cholestasis with increased gamma glutamyl transferase and phosphatase alkaline levels of 199UI/L (four times the normal rate) and 348UI/L (five times the normal rate), respectively. Transaminase levels were normal (ALAT level of 35UI/L and ASAT level of 25UI/L). A procalcitonin test was negative $(<0.5 \mu \mathrm{g} / \mathrm{L})$. Blood gas analysis was normal $(\mathrm{pH}$ level of 7.40, $\mathrm{PaO} 2$ level of $90 \mathrm{mmHg}, \mathrm{PaCO} 2$ level of $42 \mathrm{mmHg}$, HCO3- level of $25 \mathrm{mmol} / \mathrm{l})$. A chest X-ray showed a flask-shaped enlarged cardiac silhouette. Transthoracic echocardiography confirmed a non-compressive large posterior pericardial effusion. Abdominal ultrasound was normal. A thoraco-abdominal computed tomography (CT) scan showed pericardial effusion with enhancement of the pericardium, compatible with pericarditis, and regular parietal hypodense circumferential thickening of the aortic arch and supra aortic arterial trunk root, confirming aortitis (Figure 1 and Figure 2). There was emphysema in the pulmonary parenchyma but no evidence of active tuberculosis on chest $\mathrm{CT}$.

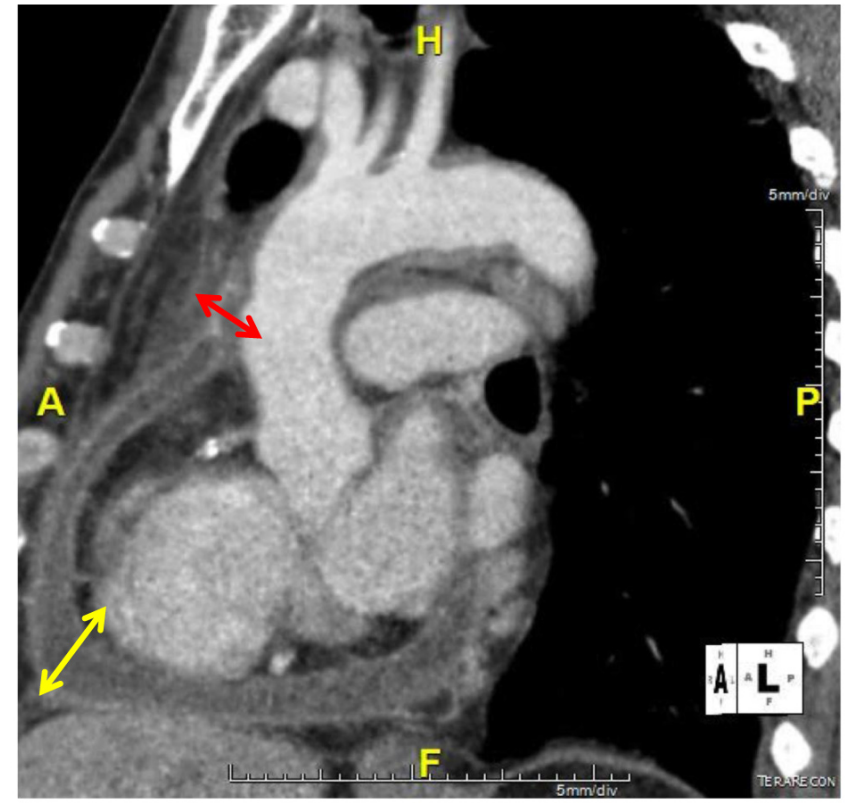

Figure 1. Thickening of the aorta (red arrow) associated with cardiac effusion (yellow arrow) in a sagittal chest CT.

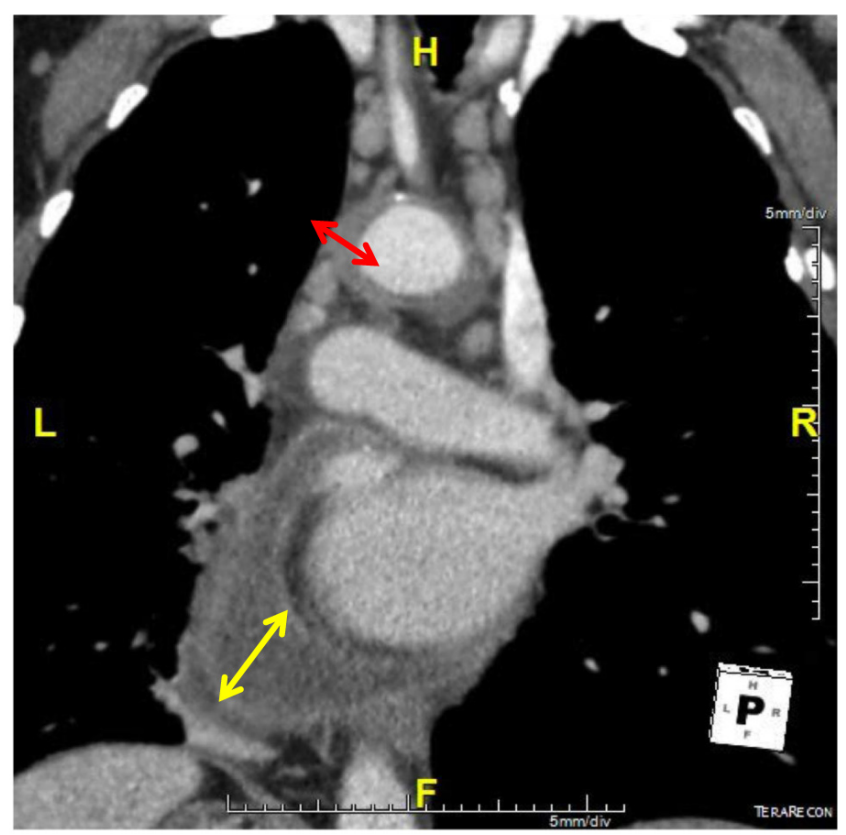

Figure 2. Thickening of the aorta (red arrow) associated with cardiac effusion (yellow arrow) in a frontal chest CT.

A biopsy of the cardiac effusion was not possible due to its posterior location. The sputum test for Koch's bacillus was negative. Viral hepatitis B and C and syphilis serology were negative. Antinuclear antibodies were positive at 1/1200. Anti-LKM1, anti-CCP and rheumatoid factor levels were $1 / 80$, $40 \mathrm{IU} / \mathrm{ml}$ and $50 \mathrm{IU} / \mathrm{ml}$, respectively. Immunoglobulin levels were normal (IgG level of $14.3 \mathrm{~g} / \mathrm{L}$, IgM level of $2.08 \mathrm{~g} / \mathrm{L}$ and IgA level of $1.8 \mathrm{~g} / \mathrm{L})$. 
Liver biopsy showed peliosis with no sign of auto-immune hepatitis nor auto-immune biliary cholangitis.

The diagnosis of RV with large vessel and cardiac involvement was retained. Disease activity was evaluated as moderate by the DAS-28 CRP score.

\section{Therapeutic intervention}

The patient was treated with a high dose of prednisone $(60 \mathrm{mg} / \mathrm{day})$ and IV pulses of $1000 \mathrm{mg}$ cyclophosphamide every month for six months. Treatment with methotrexate was stopped. Because of a personal history of pulmonary tuberculosis and the prescription of corticosteroids and cyclophosphamide in an epidemic country of tuberculosis, we administered prophylactic antitubercular therapy. The patient was also by treated with $200 \mathrm{mg} /$ day of amiodarone for the atrial fibrillation.

\section{Follow-up and outcomes}

The patient was apyretic after day 2 and their heartbeat became normal. Chest pain and articular manifestations decreased and disappeared after one month of treatment. CRP levels decreased to $12 \mathrm{mg} / \mathrm{L}$ after steroids and cyclophosphamide pulses. ESR became normal after two months of treatment. Cholestasis disappeared after one and a half months of methotrexate withdrawal.

Investigations of the cholestasis highlighted the iatrogenic involvement of methotrexate, confirmed by a report from the National Drug Safety Department in Charles Nicolle's Hospital of Tunis.

Cardiac echography showed the disappearance of the cardiac effusion at two months. A chest CT scan showed a significant regression of the vasculitis.

\section{Discussion}

The epidemiology of RV is hard to define. Heterogeneous clinical presentation, paucity of specific data to confirm the diagnosis and lack of a unanimous definition of RV are some of the reasons why it is hard to define. Many authors claim that $\mathrm{RV}$ can be observed in up to $5 \%$ of RA patients ${ }^{5}$.

Our patient was 54 years old. The mean age of patients at diagnosis of aortitis in a literature review was $56 \pm 15.2$ years old ${ }^{6}$.

RV commonly affects small and medium sized vessels. The skin is the most commonly damaged organ ( $90 \%$ of patients). The association of aortitis with RV is not widely recognized. However, many authors reported an association of RA with aortitis $^{6}$. Our patient had a lesion typical of vasculitis of the aorta on his chest CT scan. Differential diagnoses were ruled out such as syphilis, tuberculosis, systemic erythematous lupus, Takayasu's arteritis and Horton's disease.

Aortitis was the only manifestation of RV in our patient. Other similar cases have been reported. In half of the cases, aortitis was isolated, with no other features of vasculitis ${ }^{6}$.

In our patient, RV was revealed after 11 years of RA onset while the patient was treated with methotrexate and a low dose of corticosteroids. In a review of the literature, RV appeared after a mean disease duration of six years. Rheumatoid nodules were observed in up to half of patients with $\mathrm{RV}^{6}$.

Our patient had poor articular manifestations with disease activity evaluated as moderate by the DAS- 28 score. The concept of 'burnt out' disease is described by many authors, consisting of the contrast between benign articular presentation and severe life-threatening $\mathrm{RV}^{4}$. This leads us to insist on actively screening this rare but fatal complication.

RV typically occurs in long-standing seropositive and erosive RA, especially in males, smokers and patients with rheumatoid nodules or rheumatoid pericarditis ${ }^{1,5}$. Our patient had all these conditions.

There are no randomized controlled studies to guide the management of RV. However, treatment must be guided by the severity of organ involvement. High doses of corticosteroids and cyclophosphamide have been known to be the treatment of severe forms of RV such as aortitis ${ }^{1,7,6-9}$. Our patient had a good response to high doses of prednisolone and cyclophosphamide. Biotherapy such as TNF inhibitors, rituximab, abatacept and anakinra could be a good alternative $\mathrm{e}^{4,10}$.

Another particularity of our patient is his liver injury. The patient had increased gamma glutamyl transferase and phosphatase alkaline levels with normal transaminases. This cholestasis is mostly due to methotrexate. This was confirmed by the complete normalization of liver enzyme levels after methotrexate withdrawal and the report from the drug safety department. However, our patient had autoimmune hepatitis (AIH) antibodies without any histological pattern of AIH and with normal levels of transaminase and immunoglobulins. There was not enough evidence to retain the diagnosis of AIH. Furthermore, surveillance of liver biology is recommended to assess the risk of developing $\mathrm{AIH}^{11-13}$.

\section{Conclusion}

In the past years, the incidence of RV has decreased. Early diagnosis of RA, treat-to-target treatment strategies and the large use of methotrexate and biological molecules has improved the quality of life of RA patients ${ }^{5}$. Better management of the disease has led to a diminishing incidence of RV. However, clinical presentation remains unchanged. The mortality rate remains high, making RV a life-threatening condition that must be screened and treated early and aggressively. In addition, liver injury in RA patients varies from infectious (hepatitis B or C), toxic (paracetamol, methotrexate) and autoimmune.

\section{Data availability}

All data underlying the results are available as part of the article and no additional source data are required.

\section{Consent}

Written informed consent for publication of their clinical details and images was obtained from the patient. 
1. Makol A, Crowson CS, Wetter DA, et al: Vasculitis associated with rheumatoid arthritis: a case-control study. Rheumatology (Oxford). 2014; 53(5): 890-9. PubMed Abstract | Publisher Full Text | Free Full Text

2. Turesson C, O'Fallon WM, Crowson CS, et al.: Occurrence of extraarticular disease manifestations is associated with excess mortality in a community based cohort of patients with rheumatoid arthritis.

Rheumatol. 2002; 29(1): 62-7.

PubMed Abstract

3. Cojocaru M, Cohocaru IM, Chico B: New insight into the rheumatoid vasculitis. Rom J Intern Med. 2015; 53(2): 128-32.

PubMed Abstract | Publisher Full Text

4. Kishore S, Maher L, Majithia V, et al.: Rheumatoid Vasculitis: A Diminishing Yet Devastating Menace. Curr Rheumatol Rep. 2017; 19(7): 39. PubMed Abstract | Publisher Full Text

5. Genta MS, Genta RM, Gabay C: Systemic rheumatoid vasculitis: a review. Semin Arthritis Rheum. 2006; 36: 88-98. PubMed Abstract | Publisher Full Text

6. Kaneko S, Yamashita H, Sugimori Y, et al.: Rheumatoid arthritis-associated aortitis: a case report and literature review. SpringerPlus. 2014; 3: 509. PubMed Abstract | Publisher Full Text | Free Full Text

7. Makol A, Matteson EL, Warrington KJ: Rheumatoid vasculitis: an update. Curr Opin Rheumatol. 2015; 27(1): 63-70. PubMed Abstract | Publisher Full Text
8. Scott DG, Bacon PA: Intravenous cyclophosphamide plus methylprednisolone in treatment of systemic rheumatoid vasculitis. Am J Med. 1984; 76: 377-84.

PubMed Abstract | Publisher Full Text

9. Nanatsaki E, Mooney J, Scott DGI, et al.: Systemic rheumatoid vasculitis in the era of modern Immunosuppressive therapy. Rheumatology (Oxford). 2014; 53(1): 145-152.

PubMed Abstract | Publisher Full Text

10. van der Bijl $A E$, Allaart $C F$, Van Vugt J, et al.: Rheumatoid vasculitis treated with infliximab.J Rheumatol. 2005; 32(8): 1607-9. PubMed Abstract

11. Gatselis NK, Zachou K, Koukoulis GK, et al.: Autoimmune hepatitis, one disease with many faces: Etiopathogenetic, clinico-laboratory and histological characteristics. World J Gastroenterol. 2015; 21(1): 60-83. PubMed Abstract | Publisher Full Text | Free Full Text

12. Weinblatt $M E$, Tesser JR, Gilliam JH 3rd: The liver in rheumatic diseases. Semin Arthritis Rheum. 1982; 11(4): 399-405. PubMed Abstract

13. Utiyama SRR, Zenatti KB, Nóbrega HAJ, et al:: Rheumatic Disease Autoantibodies in Autoimmune Liver Diseases. Immunol Invest. 2016 45(6): 566-73.

PubMed Abstract | Publisher Full Text 


\section{Open Peer Review}

\section{Current Peer Review Status: ? ?}

\section{Version 1}

Reviewer Report 29 March 2021

https://doi.org/10.5256/f1000research.29744.r80665

(C) 2021 Kaneko S. This is an open access peer review report distributed under the terms of the Creative Commons Attribution License, which permits unrestricted use, distribution, and reproduction in any medium, provided the original work is properly cited. The author(s) is/are employees of the US Government and therefore domestic copyright protection in USA does not apply to this work. The work may be protected under the copyright laws of other jurisdictions when used in those jurisdictions.

\section{Shunta Kaneko}

Division of Rheumatic Diseases, Tokyo Yamate Medical Center, Tokyo, Japan

Teyeb et al. reported a rare case of aortitis in patients with rheumatoid arthritis. While the treatment of rheumatoid arthritis has made remarkable progress, this paper is interesting and important especially because aortitis is a life-threatening condition. I have several minor comments:

1. Diagnostic assessment: The RF titer of this patient was low for rheumatoid vasculitis. Does the patient have any findings suggestive of rheumatoid vasculitis such as interstitial pneumonia, skin ulcers, and low complement except for rheumatoid nodules? Without these findings, the possibility of Takayasu's arteritis and extracranial giant cell arteritis can't be ruled out.

2. Follow-up and outcomes: Do you have follow-up CT images? You should show an improvement in the thickening of the aortic wall by CT.

Is the background of the case's history and progression described in sufficient detail? Yes

Are enough details provided of any physical examination and diagnostic tests, treatment given and outcomes?

Partly

Is sufficient discussion included of the importance of the findings and their relevance to future understanding of disease processes, diagnosis or treatment? Partly

Is the case presented with sufficient detail to be useful for other practitioners? 
Partly

Competing Interests: No competing interests were disclosed.

Reviewer Expertise: Rheumatology

I confirm that I have read this submission and believe that I have an appropriate level of expertise to confirm that it is of an acceptable scientific standard, however I have significant reservations, as outlined above.

Reviewer Report 16 December 2020

https://doi.org/10.5256/f1000research.29744.r75567

(C) 2020 Galarza-Delgado D. This is an open access peer review report distributed under the terms of the Creative Commons Attribution License, which permits unrestricted use, distribution, and reproduction in any medium, provided the original work is properly cited.

\section{Dionicio Ángel Galarza-Delgado}

Rheumatology Service and Internal Medicine Department, Hospital Universitario "Dr. José Eleuterio González", Monterrey, Mexico

I have read this article with interest.

The title of the article is presented as the association of aortitis with rheumatoid arthritis, it should be noted that there would also be an association between the patient's history of tuberculosis with aortitis, perhaps the title could be modified.

Other causes of infectious aortitis are not discussed in your article.

Please see:

Journeau L, de la Chapelle M, Guimard T, Ferfar Y, Saadoun D, Mahé I, Castier Y, Montravers P, Lescure X, Van Gysel D, Asseray N, Lascarrou JB, Ngohou C, Vandamme YM, Connault J, Cepoy PD, Brochard J, Goueffic Y, Pistorius MA, Boutoille D, Espitia O. A strobe multicenter descriptive study of 55 infectious aortitis. Medicine (Baltimore). 2020 Oct 2;99(40):e22422 ${ }^{1}$..

For example, among rare infectious causes is a infection by $\mathrm{C}$ burnetii which usually occurs in men aged over 50 and lived in rural environment.

You do not mention whether fungal causes were ruled out as rare causes of aortitis.

It is noteworthy that there were no or no other common manifestations of rheumatoid vasculitis such as skin ulcerations, erythema nodosum, and only "vasculitis" of large vessels was found in his patient.

It is not mentioned whether there was evidence of atherosclerosis or aneurysm given the age of the patient. Please clarify.

It is not mentioned whether positron emission tomography (PET) -CT was done to rule out other sites of vascular involvement. Please clarify.

You could specify in your article if the aortic vascular affection was concentric or localized, if there were any Sacciform aneurysm.

Also determine if in the imaging studies there was presence of gas bubbles in or around the aorta wall or mural thrombus. As well as whether blood cultures were taken to detect rare 
and sometimes indolent infectious causes such as Salmonella infections of the aorta in patients with atherosclerosis

Please see. Looi JL, Cheung L, Lee AP. Salmonella mycotic aneurysm: a rare cause of fever and back pain in elderly. Int J Cardiovasc Imaging. 2013 Mar;29(3):529-312.

Finally, you say in your article that giant cell arteritis was excluded, but it is not mentioned how it was excluded. Please expand the discussion on other causes of non-infectious aortitis.

Please see.

Loricera J, Blanco R, Hernández JL, Carril JM, Martínez-Rodríguez I, Canga A, Peiró E, AlonsoGutiérrez J, Calvo-Río V, Ortiz-Sanjuán F, Mata C, Pina T, González-Vela MC, Martínez-Amador N, González-Gay MA. Non-infectious aortitis: a report of 32 cases from a single tertiary centre in a 4year period and literature review. Clin Exp Rheumatol. 2015 Mar-Apr;33(2 Suppl 89):S-19-31. ${ }^{3}$.

\section{References}

1. Journeau L, de la Chapelle M, Guimard T, Ferfar Y, et al.: A strobe multicenter descriptive study of 55 infectious aortitis.Medicine (Baltimore). 2020; 99 (40): e22422 PubMed Abstract | Publisher

Full Text

2. Looi JL, Cheung L, Lee AP: Salmonella mycotic aneurysm: a rare cause of fever and back pain in elderly.Int J Cardiovasc Imaging. 2013; 29 (3): 529-31 PubMed Abstract | Publisher Full Text 3. Loricera J, Blanco R, Hernández JL, Carril JM, et al.: Non-infectious aortitis: a report of 32 cases from a single tertiary centre in a 4-year period and literature review.Clin Exp Rheumatol. 33 (2 Suppl 89): S-19 PubMed Abstract

Is the background of the case's history and progression described in sufficient detail? Yes

Are enough details provided of any physical examination and diagnostic tests, treatment given and outcomes?

Yes

Is sufficient discussion included of the importance of the findings and their relevance to future understanding of disease processes, diagnosis or treatment?

Yes

Is the case presented with sufficient detail to be useful for other practitioners? Yes

Competing Interests: No competing interests were disclosed.

Reviewer Expertise: Rheumatology

I confirm that I have read this submission and believe that I have an appropriate level of expertise to confirm that it is of an acceptable scientific standard, however I have significant reservations, as outlined above. 
The benefits of publishing with F1000Research:

- Your article is published within days, with no editorial bias

- You can publish traditional articles, null/negative results, case reports, data notes and more

- The peer review process is transparent and collaborative

- Your article is indexed in PubMed after passing peer review

- Dedicated customer support at every stage

For pre-submission enquiries, contact research@f1000.com 